\title{
Research of mental health of elderly people in post-labor period of life
}

\author{
Svetlana Taysaeva $^{1}$, Liudmila Shukshina ${ }^{1 *}$, Olga Kamneva $^{2}$, Natalia Skripnikova ${ }^{3}$, and \\ Madina Gazzayeva ${ }^{4}$ \\ ${ }^{1}$ FSBEI HE Plekhanov Russian University of Economics, 117997, Moscow, Russian Federation \\ ${ }^{2}$ FSBEI HE Astrakhan State University, 414056, Astrakhan, Russian Federation \\ ${ }^{3}$ Egoriev Branch of the Federal State Budgetary Educational Institution of Higher Education Moscow \\ Pedagogical State University, 140300, Yegoryevsk, Russian Federation \\ ${ }^{4}$ South Ossetian State University Named after A.A. Tibilov, 100001, Tskhinval, South Ossetia
}

\begin{abstract}
Preservation of mental health in old age is an important area of research in modern psychology and psychiatry. The article discusses possible reasons for the decline in mental health of elderly people and the search for factors that would contribute to the preservation of mental health in the post-labor period. It is noted that a significant role herein is given to environmental factors. The study showed that self-acceptance, acceptance of others, internality, optimal level of self-esteem (adequacy), moderate external activity, self-realization, emotional comfort, optimistic attitude to the future, interest in social problems are the main factors of mental health preservation in old age. Women are more socialized in society than men, so men are more likely to be at risk.
\end{abstract}

\section{Introduction}

In the process of aging, at first glance there are two contradictory processes: on the one hand, the body restricts the mechanisms of self-regulation, on the other hand - it mobilizes reserve mechanisms by which the body of older people acquires the necessary homeostasis $[1,2]$. The condition for acquiring such homeostasis is primarily mental health $[3,4]$. The mental health of an elderly person consists of the ability to respond adequately to internal and external stimuli, the ability to manage own emotional sphere, understand own emotions, opportunities for self-development [5,6]. The causes of mental health disorders can be associated with both somatic weakness and environmental factors [7]. Many elderly people in the post-labor period orient themselves on a passive lifestyle, "survival", which leads to a deterioration of not only physical condition, but also a decrease in psychological comfort $[8,9]$. Consequently, the mental and physical health of an elderly person is closely related and requires closer examination.

The purpose of the study is to determine the factors that contribute to improving the mental health of elderly people in the post-labor period.

\footnotetext{
${ }^{*}$ Corresponding author: liudmila.shukshina@yandex.ru
} 


\section{Materials and methods}

The study involved 120 people: 60 men and 60 women aged from 56 to 67 years, who retired and did not work at the time of the study.

To study the indicators of mental health that we are interested in, we used the following methods: diagnostics of social and psychological adaptation by K. Rogers and R. Diamond, "Personal differential" (PD) (adapted in the SRD n.a. V. M. Bekhterev), Test of unfinished sentences (based on the methodology of J. Nutten), test "Social and psychological adaptation" (variant of A.K. Osnitsky), "Acceptance of others" scale.

The Student's criterion (t-criterion) and Fischer's criterion ( $\varphi^{*}$ - angular transformation) were used during statistical processing of the obtained results. Statistical processing of the empirical study results was performed using Microsoft Excel 2019 program and the integrated statistical package SPSS Statistics 22.

\section{Results and discussion}

At the initial stage of the study respondents were asked the following questions:

1. Your age?

2. Your education?

3. Who did you work for before retirement?

4. Term of your employment.

5. Do you have family?

6. Has your life changed for the better in Your life now?

7. Has anything changed for the worse in Your life now?

8. What do you prefer to do in retirement?

9. How satisfied are you with communicating with other people?

10. What is old age for you?

According to the results of the survey, three test groups were identified. The first group (a) included subjects who subjectively assessed their status positively and were satisfied with their real life. The second group (b) - elderly people who are subjectively neutral about their age on the principle of "what is to be, is not to be avoided". In the third group (c) there were subjects who are not satisfied with their situation and have a negative attitude to their age and social status.

The work was carried out separately with each group, using the same research methods presented above.

The study showed that the group "a" evaluates their appearance positively, believes that they are able to cope with difficulties on their own, their life is interesting and full. The respondents of this group have a significantly high level of self-acceptance on the scale of the integral indicator "self-acceptance" of the social and psychological adaptation method of K. Rogers and R. Diamond compared to group "b"- $t_{s t} \leq 10.04 ; p<0.01$ and group "c" $\mathrm{t}_{\mathrm{st}} \leq 10.31 ; \mathrm{p}<0.01$.

To study the localization of respondents control, the integrative indicator "internality" was used. It was found that the average $t_{s t} \leq 10.7$ at $p<0.05$ and high $t_{s t} \leq 9.8$ at $p<0.01$ values of this indicator are equally present in both men and women. This indicates that people with a high level of social and psychological adaptation after retirement believe that most of the important events in their life are the result of their own work, efforts and it depends on them how their life will turn out in the future. Gender differences in the "internality" criterion are not statistically significant.

Subjects, both men and women with a high level of social and psychological adaptation have an optimal level of self-esteem in comparison with the subjects of group " $b "-t_{s t} \leq 9.7$; $\mathrm{p}<0.05$ and group "c" $-\mathrm{t}_{\mathrm{st}} \leq 18.8 ; \mathrm{p}<0.01$. It can be assumed that people in group "a" 
consider their life as satisfactory. They made deliberate actions, were responsible for them, their life path is realized.

The results of the study using the Personal differential method showed that $67 \%$ of the subjects in group "a" have an optimal level of self-esteem for the factor "strength" compared to group "b" - $t_{s t} \leq 7.02 ; p<0.05$ and group "c" $-t_{s t} \leq 12.4 ; p<0.01$. This means that people in group "a" are confident, self-reliant, and independent in difficult situations. The indicators of the "evaluation" factor in the group are also high compared to the same indicator in the group " $b "-t_{s t} \leq 13.6 ; p<0.01$ and in group "c" $-t_{s t} \leq 21.9 ; p<0.01$. Subjects are aware of themselves as carriers of socially desirable characteristics and, therefore, are useful to society. According to the "activity" factor, the subjects of the groups "a" are superior to groups "b" and "c" - $\mathrm{t}_{\mathrm{st}} \leq 9.7$ at $\mathrm{p}<0.05$ and $\mathrm{t}_{\mathrm{st}} \leq 5.9$ at $\mathrm{p}<0.05$ respectively.

Using the Fisher $\varphi$-criterion, differences in the factors "strength" and "evaluation" were identified. For the subjects of group "a" the average values of indicators prevail by the factor "strength"; by the factor "evaluation" they are high. It can be assumed that the subjects of group "a" put their socially desirable characteristics higher than their strongwilled qualities.

There were gender differences in factors - men rated their strong-willed qualities and self-confidence higher than women of the same group $\mathrm{t}_{\mathrm{st}} \leq 14.4$ at $\mathrm{p}<0.01$. While women significantly higher than men rated their social qualities $t_{\mathrm{st}} \leq 10.9$ at $\mathrm{p}<0.05$ and the level of achievement $\mathrm{t}_{\mathrm{st}} \leq 19.3$ at $\mathrm{p}<0.01$.

These results indicate a high level of adaptation of elderly people in the post-labor period.

The subjects of group "b" (76\%) have an average value of the indicator on the scale of "self-acceptance" (the method of social and psychological adaptation of K. Rogers and R. Diamond) compared to the indicators of the group "c" $\left(\mathrm{t}_{\mathrm{st}} \leq 16.8\right.$ at $\left.\mathrm{p}<0.01\right)$. No statistically significant sex differences were found.

The results were analyzed using the "Personal differential" method based on the following factors: "strength", "evaluation" and "activity". The analysis of the results by factors showed that the majority of subjects in group " $b$ " had the optimal level of selfesteem by the factor "strength". But there were significant differences from groups "a" and "c" $-t_{\text {st }} \leq 15.8$ at $\mathrm{p}<0.01$ and $\mathrm{t}_{\mathrm{st}} \leq 12.9$ at $\mathrm{p}<0.01$, respectively. For the "evaluation" factor and the "activity" factor, the indicators also significantly differ from the indicators of the factors of the groups "a" and "c" subjects for the "evaluation" factor in comparison with group "a" $-\mathrm{t}_{\mathrm{st}} \leq 17.9 ; \mathrm{p}<0.01$, group "c" $\mathrm{t}_{\mathrm{st}} \leq 13.6 ; \mathrm{p}<0.05$ and for the "activity" factor $\mathrm{t}_{\mathrm{st}}$ $\leq 14.7 ; \mathrm{p}<0.05$ and $\mathrm{t}_{\mathrm{st}} \leq 17.8 ; \mathrm{p}<0.01$.

It was found that the subjects of group " $\mathrm{b}$ " tend to overestimate their social qualities in comparison with the subjects of the group "a". Men did not show low values for the "strength" factor, while $18 \%$ of women have these indicators. It can be assumed that men tend to exaggerate their strong-willed qualities, while women underestimate them $-t_{s t} \leq$ 20.4; $\mathrm{p}<0.01$.

Women are more likely than men to have very high values for the "activity" factor $-t_{s t} \leq$ $17.4 ; \mathrm{p}<0.01$, i.e. in all groups, women are more social than men.

When analyzing the results on the "internality" scale, it was determined that the majority of elderly people in group "b" have this indicator higher than those in group "c" $\mathrm{t}_{\mathrm{st}} \leq 7.8 ; \mathrm{p}<0.05$. It can be assumed that this group of respondents relies on their own strength in a familiar adaptive environment and are maladaptive in a new one. At this point, they tend to blame the circumstances or other people for the situation and wait for help from others, without solving the problem by themselves.

The majority of subjects in group "c" have a low level of "self-acceptance" (73\% of subjects) compared to those in group "b" $-t_{s t} \leq 16.4 ; p<0.01$. It was determined that 
women with a low level of social and psychological adaptation tend to have a low value of the "self-acceptance" indicator (about $65 \%$ of the subjects), while men in all cases $-t_{\mathrm{st}} \leq$ 20.6 at $p<0.01$ and $t_{s t} \leq 19.7 ; p<0.01$, respectively. According to the "strength" factor, the majority of subjects in group "c" had low values - 63\% of the subjects. According to the "assessment" and "activity" factors, the maximum number of average values is observed in $78 \%$ of the subjects. Representatives of the group "c" has dominant low values of selfesteem. Especially low subjects of this group evaluate their strong-willed qualities.

Statistical differences in the "strength" and "evaluation" factors were found in men and women. Men with a low level of social and psychological adaptation (85\%) also have a low assessment of their strong-willed qualities. Only $16 \%$ of women in this group believe that their strong-willed qualities are not enough to overcome life's difficulties and others place too high demands on them that cannot be met. The majority of elderly people in group "c" have a low level of internality - 74\%. This criterion shows the measure of independence and initiative, activity and effort in achieving their own goals. This category is characterized by such qualities as destitution of all principles, anxiety, conformity, and deceitfulness.

The method of incomplete sentences was used to study the motivational-need sphere.

In the statements of the group "a" subjects about the future, the expectation of achievement is more common (34\%) than in group "b" $(15 \%)$ at $\varphi^{*}=2.504 ; p \leq 0.01$ and in group "c". In group "b", a large percentage of the responses of subjects $-73 \%$, both men and women, is associated with solving household problems, than in group "a" $\varphi^{*}=1.78$; $\mathrm{p} \leq 0.05$. In statements about the past, the group "a" subjects more often - 57\%, than the subjects of group "b" and "c" note that they realized their plans, realized themselves $\varphi^{*}=2.49 ; \mathrm{p} \leq 0.01$ and $\varphi^{*}=2.68 ; \mathrm{p} \leq 0.01$.

Subjects of group "c" more often - $42 \%$, than group "a" subjects - $2 \%$ and group "b" $7 \%-\varphi^{*}=2.46 ; p \leq 0.01$ note that there were more failures in life than achievements and successes. Many respondents in group "c" are disappointed that they did not realize what they had planned or did not realize a dream they had in their youth. Reliable indicators were observed between groups "a" and "c" $-\varphi^{*}=2.95 ; \mathrm{p} \leq 0.01$.

In group "b", $38 \%$ of the subjects noted that they could only partially implement their professional activities. Compared with group "C", this indicator is significantly higher in men and women $-\varphi^{*}=2.89 ; \mathrm{p} \leq 0.01$. In statements related to retirement, group "c" subjects more often $(64 \%)$ than group "a" subjects $(30 \%)$ noted that they experience retirement age as the loss of their Self, connections in society, age of past hopes $-\varphi^{*}=2.547 ; p \leq 0.01$. Describing the attitude to relatives, the subjects of group "a" readily express a desire to take care of their relatives $-\varphi^{*}=2,622 ; p \leq 0.01$.

Elderly people in group "c" feel the need for social connections, but at the same time fear being left alone due to low social contacts. the respondents in group "a" do not feel this fear, even if they have to stay alone and perceive old age as an inevitable, but at the same time effective stage of individual life.

The definition of old age as caring for loved ones is less common in group " $b$ " than in group "c" $-\varphi^{*}=2.539 ; p \leq 0.05$ and group "a" $-\varphi^{*=2.956 ;} \mathrm{p} \leq 0.05$. Significant differences in indicators were found on the scale "acceptance of others". Elderly people in group "a" have a high level of acceptance of others compared to subjects in group " $b^{\prime \prime}-\varphi^{*}=2.581 ; p \leq 0.01$.

Thus, elderly people of group "a" have a high level of social and psychological adaptation in the post-labor period. They are moderately active, optimistic about the future, positive about the past, and fully accept themselves as they are. The study of the emotional sphere of the subjects showed that the representatives of group "a" are characterized by a high level of emotional comfort in comparison with group "c" at the level of significance $\varphi^{*}=3,672 ; p \leq 0.01$. In group "c" low level of emotional comfort is significantly more common compared to group "b"- $\varphi^{*}=2.788 ; \mathrm{p} \leq 0.01$, and to group "a" $-\varphi^{*}=2.898 ; \mathrm{p} \leq 0.01$. 
In group "b", the fear of not having time to do something is more common than in group "c" $-\varphi^{*}=2,782 ; p \leq 0.05$.

In $54 \%$ of cases, the subjects of group "a" have anxiety for their loved ones, compared to the indicators of group "c" $-\varphi^{*}=2.367 ; \mathrm{p} \leq 0.05$. Elderly people in the third group are more likely to experience the fear of becoming a burden to relatives compared to the subjects in the "c" group - $\varphi^{*}=2,827 ; p \leq 0.05$. Group " $c^{\prime}$ is rarely interested in the problems of society, which is why they often remain isolated and rarely communicate even with relatives.

\section{Conclusion}

Thus, the factors that contribute to improving the mental health of elderly people in the post-labor period are identified. These are self-acceptance, acceptance of others, internality, optimal level of self-esteem (adequacy), moderate external activity, self-realization, emotional comfort, optimistic attitude to the future, interest in social problems. At the same time, old age is a new stage in a person's life.

\section{References}

1. M. V. Kandelya, L.A. Koysman, V.P. Nazarova, Bulletin of the Amur State University n.a. Sholem-Aleichem, 3, 96-103 (2018)

2. S. N. Kozlovskaya, Ya.V. Shimanovskaya, Scientific notes of the Russian State Social University, 15, 6 (139), 71-77 (2016)

3. E. A. Sergienko, RSUH Bulletin, Series: Psychology. Pedagogy. Education, 4, 98-117 (2017)

4. V. N. Shabalin S.N. Shatokhina, Ulyanovsk medical and biological journal, 3, 124-132 (2018)

5. O. M. Razumnikova, L.V. Prokhorova, A.A. Yashanina, Advances in gerontology, 2, 353-359 (2016)

6. E.A. Sergienko, N.S. Pavlova, Bulletin of the Russian Foundation for Basic Research, 4 (104), 59-68 (2019)

7. L. V. Litvinova, V. Ya. Gorbunkov, Gender features of psychological adaptation in elderly people, Collection: Topical issues of geriatrics. Materials of the 8th Interregional Scientific and Practical Conference, 37-41 (2016)

8. S. G. Maximova, B. G. Lunitsin, Clinical gerontology, 7, 38-45 (2001)

9. L. I. Starovoitova, I. E. Feldkoren, Social and psychological adaptation and problems of socialization of elderly people in modern society, Collection: Professionalism and creativity in social work, 149-154 (2016) 